\title{
Determination of Flavonoids and Phenolic Acids in Plant Materials Using SLE-SPE-UHPLC-MS/MS Method
}

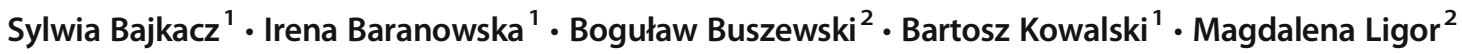

Received: 31 January 2018 / Accepted: 22 July 2018 / Published online: 6 August 2018

(C) The Author(s) 2018

\begin{abstract}
Today, great emphasis is placed on the search for and dissemination of native plant materials in various industries, with particular emphasis on food, cosmetics, dietary supplements, and as livestock feed and a source of biomass. Solid-liquid extraction (SLE), solid phase extraction (SPE), and ultra-high-performance liquid chromatography coupled with tandem mass spectrometry (UHPLC-MS/MS) methods were developed for the simultaneous determination of 30 flavonoids and phenolic acids in plant materials (lucerne (Medicago sativa L.), goldenrod (Solidago virgaurea L.), phacelia (Phacelia tanacetifolia Benth.), buckwheat (Fagopyrum esculentum), licorice (Glycyrrhiza glabra), and lavender (Lavandula spica L.)). Different SLE methods were tested to evaluate their applicability for the isolation of polyphenols from plants. Then extracts were purified with a C18 reversed-phase SPE cartridge. After extraction, samples were analyzed by UHPLC-MS/MS. The SLE-SPE-UHPLC-MS/MS assay method has been fully validated. For the most compounds, good recoveries and RSDs $(<10 \%)$ were obtained. Limits of quantification range from 0.4 to $20 \mathrm{ng} / \mathrm{mL}$. The main phenolic acids in the studied plants have been found to be 3-(4-hydroxyphenyl)propionic acid, 4-hydroxybenzoic acid, and 3,4-dihydroxybenzoic acid. Quercetin, rutin, glabridin, and naringenin are the major flavonoids detected in the analyzed samples. The obtained scientific data can be useful to select plant materials with high nutritional value and the presence of many biologically active ingredients, as well as selecting samples used as a plant biomass, as food, and as a component of dietary supplements.
\end{abstract}

Keywords Flavonoids $\cdot$ Phenolic acids $\cdot$ Plant $\cdot$ UHPLC-MS/MS · Extraction

\section{Introduction}

Phenolic compounds, ubiquitous in plants, are an essential part of the human diet and animal feed and are of considerable interest due to their antioxidant properties. These compounds, one of the most widely occurring groups of phytochemicals, are of considerable physiological and morphological importance in plants. In plant, phenolics may act as phytoalexins,

Electronic supplementary material The online version of this article (https://doi.org/10.1007/s12161-018-1332-9) contains supplementary material, which is available to authorized users.

Irena Baranowska

irena.baranowska@polsl.pl

1 Department of Inorganic, Analytical Chemistry and Electrochemistry, Faculty of Chemistry, Silesian University of Technology, M. Strzody 7 Str., 44-100 Gliwice, Poland

2 Department of Environmental Chemistry and Bioanalytics, Faculty of Chemistry, Nicolaus Copernicus University, Gagarin 7 Str., 87-100 Torun, Poland antifeedants, attractants for pollinators, contributors to the plant pigmentation, antioxidants, and protective agents against UV light (Treuter 2006).

In food, phenolics may contribute to the bitterness, astringency, color, flavor, odor, and oxidative stability of products. In addition, the health-protecting capacity of some phenolics and the wide range of physiological properties, such as antiallergenic, anti-atherogenic, anti-inflammatory, anti-microbial, antioxidant, anti-thrombotic, cardioprotective, and vasodilatory effects, of other plant phenolics are of great importance to producers, processors, and consumers. Fruits, vegetables, nuts, seeds, flowers, bark, and beverages are common sources for polyphenols in human diets and in animal nutrition (Shahidi and Ambigaipalan 2015).

Today, great emphasis is placed on the search for and dissemination of native plant materials in various industries, with particular emphasis on cosmetics, dietary supplements, and as livestock feed and a source of biomass. Selected plant materials should have both nutritional value and the presence of biologically active ingredients, especially antioxidants. For this purpose, it is necessary to determine biologically active 
compounds (e.g., polyphenols) in raw plant materials. Those plant materials which meet the aforementioned criteria and which also contain important active ingredients are lucerne (Medicago sativa L.), licorice (Glycyrrhiza glabra), goldenrod (Solidago virgaurea L.), buckwheat (Fagopyrum esculentum), phacelia (Phacelia tanacetifolia Benth.) and lavender (Lavandula spica L.). In the literature, there is information about the potential antioxidant activity of these plants; however, only little information is available about the content of polyphenols (Velioglu et al. 1998).

Chromatographic techniques combined with different detectors are preferred to individually identify and quantify phenolic compounds in the above plants. Detection of polyphenols in plant material (buckwheat (Kreft et al. 2006), lucerne (Martin et al. 2006), licorice (Wang and Yang 2007), goldenrod (Apáti et al. 2002) has been performed with a UV-Vis detector, because the conjugated double and aromatic bonds allow phenolics to absorb in UV or UV-Vis regions. A diode array detector (DAD) is also often used, because it gives more information when complex mixtures are present in the plant extracts of lavender (Areias et al. 2000), lucerne (Goławska et al. 2010a, b), licorice (Siracusa et al. 2011), and goldenrod (Sabir et al. 2012). Other methods used for the detection of rutin and catechins in buckwheat include an electrochemical coulometric array detector (EC) (Danila et al. 2007). Highperformance liquid chromatograph coupled with mass spectrometry has commonly been used for structural characterization of phenolics (Marczak et al. 2010). Electrospray ionization mass spectrometry (ESI-MS or ESI-MS/MS) has been employed for structural confirmation of phenolics in Medicago truncatula (Farag et al. 2007), Glycyrrhiza glabra (Montoro et al. 2011), and Glycyrrhiza uralensis and Glycyrrhiza glabra (Liao et al. 2012). When qualitative analysis has to be performed, the highest resolution for identification purposes is provided by time-of-flight (TOF) mass spectrometers (Verardo et al. 2010).

Besides liquid chromatography, nuclear magnetic resonance spectroscopy (NMR) has also been used due to its being another technique that allows unequivocal information on phenolics. ${ }^{1} \mathrm{H}$ NMR and ${ }^{13} \mathrm{C}$ NMR were used by Farag et al. (2012) to identify the major phenolic compounds in Glycyrrhiza glabra, Glycyrrhiza uralensis, Glycyrrhiza inflata, and Glycyrrhiza echinata roots. In some cases, gas chromatographic and capillary electrophoresis techniques was employed for separation and quantitation of flavonoids and isoflavonoids in roots and cell suspension cultures of Medicago truncatula (Farag et al. 2007), rutin in Fagopyrum esculentum (Kreft et al. 1999), and five flavonoids in licorice (Chen et al. 2009).

Simultaneous quantification of flavonoids and phenolic acids in plant materials in a single operation is much more convenient than using several separate procedures, especially for routine analysis or for a large number of samples. One of the greatest advantages is the simplification of the overall analytical process, for example, by reducing the frequency of changing the separation system and the number of mobile phase preparations. Moreover, most of the literature-revealed analytical methods do not appear to have validated the analytical methodology involved or have been applied to determination of polyphenols only in one plant.

Based on the aim of the current study, a reversed-phase ultra-high-performance liquid chromatography coupled with a tandem mass spectrometry (UHPLC-MS/MS) method for simultaneous quantification of 30 polyphenols (flavonoids and phenolic acids) in six different plant materials (lucerne, goldenrod, phacelia, buckwheat, licorice, and lavender) was developed.

The developed method, which allows to simultaneous determine a wide spectrum of flavonoids from various chemical/ structural groups, can be certainly useful for the analysis of plant materials, used to a small extent for human consumption. Lucerne, goldenrod, phacelia, buckwheat, licorice, and lavender, known primarily as feed components, could be also widely used as food supplements or ingredients of other food products, due to the content of antioxidants, which are important for health. Moreover, it should be noted that these materials are readily available and cheap.

\section{Experimental}

\section{Chemicals and Reagents}

Chrysin (CHS) (used as an internal standard; IS), rutin (RUT), hesperetin (HST), quercetin (QUE), naringenin (NAR), naringin (NARG), narirutin (NRT), hesperidin (HSD), neohesperidin (NHSD), pinocembrin (PIN), taxifolin (TAX), fisetin (FIS), glabridin (GLB), eriocitrin (ERC), eriodictyol (ERI), formononetin (FOR), liquiritin (LIQ), liquiritigenin (LQG), 3-hydroxybenzoic acid (3-HBA), benzoic acid (BA), caffeic acid (CA), 3,4-dihydroxybenzoic acid (3,4-DHBA), hippuric acid (HA), $\alpha$-hydroxyhippuric acid ( $\alpha$-HHA), 3-(4-hydroxyphenyl)propionic acid (3,4-HPPA), 4-hydroxybenzoic acid (4-HBA), 3,4-dihydroxy-phenylacetic acid (DOPAC), 3-hydroxyphenylacetic acid (3-HPA), $p$-coumaric acid ( $p$-COA), ferulic acid (FA), and 4-hydroxy3-methoxyphenylacetic acid (HVA) were purchased from Sigma-Aldrich (Saint Louis, USA). Formic acid (HCOOH) and acetonitrile (ACN) for LC-MS from Merck (Darmstadt, Germany) were used for mobile phase preparation. Ethanol $(\mathrm{EtOH})$ and methanol $(\mathrm{MeOH})$, both from Chempur (Piekary Slaskie, Poland), and hydrochloric acid $(\mathrm{HCl})$ from Stanlab (Lublin, Poland) were used for sample treatment optimization. Purified water from a Milli-Q Element A10 System (Millipore, Milford, MA, USA) was used in the preparation of the mobile phase, for sample preparation and reagent solutions. 


\section{Stock Solutions, Calibration Standards, and Quality Control Samples}

Standard stock solutions of flavonoids and phenolic acids were prepared by dissolving the analytes in methanol, obtaining concentrations of $1.0 \mathrm{mg} / \mathrm{mL}$. Working solutions for calibration standards (CS) and quality control (QC) samples were prepared by diluting stock solutions of analytes with methanol, which resulted in the polyphenols working solution with a concentration of $1000,500,250,100$, and $20 \mathrm{ng} / \mathrm{mL}$. Stock solutions and working solutions were stored in a refrigerator at $4{ }^{\circ} \mathrm{C}$.

Calibration standards (CSs) were prepared at ten levels, ranging from 1 to $1000 \mathrm{ng} / \mathrm{mL}$, by dilution of the polyphenol working solutions with methanol. Quality control (QC) samples for method validation were prepared in the same way as calibration standards and at three concentration levels of polyphenols: $1 \mathrm{ng} / \mathrm{mL}$ (low quality control, LQC), 40-100 ng/mL (medium quality control, MQC), and $80-800 \mathrm{ng} / \mathrm{mL}$ (high quality control, HQC). Additionally, dilution integrity was studied in a sample spiked at $80-800 \mathrm{ng} / \mathrm{mL}$ (depending on compounds). Aliquots of all standards were stored in a refrigerator at $4{ }^{\circ} \mathrm{C}$ until further use.

\section{Plant Material}

Lucerne (M. sativa L.), plants of a species belonging to the bean family, were harvested in the flowering season from plantations located (without the use of agrotechnical) in Kołuda Wielka (Kuyavian-Pomeranian Province) in June 2016. Goldenrod (S. virgaurea L.), wild plants, were collected near in the vicinity of Torun (Kuyavian-Pomeranian Province) in August-September 2016. Phacelia (P. tanacetifolia Benth.), agricultural crops, without agronomic treatments, were collected near Bobrowniki (Kuyavian-Pomeranian Province) in August 2016. Raw materials were divided into morphological parts: flowers, leaves, and stalks (lucerne and goldenrod) and flowers, leaves, stalks, and roots (phacelia). The segregated material was dried at ambient temperature, without light, and then ground in a ball mill. Powdered material was stored in glassware without light.

Buckwheat (F. esculentum), licorice (G. glabra), and lavender ( $L$. spica L.) were obtained from various local herbal markets.

\section{Sample Preparation}

Sample treatment was studied using six different plant materials: lucerne, goldenrod, phacelia, buckwheat, licorice, and lavender. Eight different protocols were studied to obtain the maximum recovery of flavonoids and phenolic acids from plants. The following were tested: solid-liquid extraction (SLE) using $\mathrm{H}_{2} \mathrm{O}$, shaking for $5 \mathrm{~h}$ (ST1); mixture $\mathrm{H}_{2} \mathrm{O}$ /
EtOH $(1: 1 ; v / v)$, shaking for $2 \mathrm{~h}(\mathrm{ST} 2)$; mixture $\mathrm{H}_{2} \mathrm{O} / \mathrm{EtOH}$ $(1: 1 ; v / v)$, shaking for $5 \mathrm{~h}(\mathrm{ST} 3)$; EtOH, shaking for $5 \mathrm{~h}$ (ST4); mixture $\mathrm{H}_{2} \mathrm{O} / \mathrm{MeOH}(1: 1 ; v / v)$, shaking for $2 \mathrm{~h}$ (ST5); mixture $\mathrm{H}_{2} \mathrm{O} / \mathrm{MeOH}(1: 1 ; v / v)$, shaking for $2 \mathrm{~h}$ two times (ST6); mixture $\mathrm{H}_{2} \mathrm{O} / \mathrm{MeOH}(1: 1 ; v / v)$, shaking for $5 \mathrm{~h}(\mathrm{ST} 7)$; and $\mathrm{MeOH}$, shaking for $5 \mathrm{~h}$ (ST8).

For protocols S1-S8, each plant material was previously crushed and homogenized and approximately $2.5 \mathrm{~g}$ was accurately weighed. Samples were extracted with $10 \mathrm{~mL}$ (for phacelia, lucerne, and licorice) or $20 \mathrm{~mL}$ (for lavender, goldenrod, and buckwheat) of $\mathrm{MeOH}$ for $5 \mathrm{~h}$ at $900 \mathrm{rpm}$, using an automatic shaker (SLE) (Vibramax 100, Heidolph Instruments $\mathrm{GmbH} \& \mathrm{Co}$.). The extract was filtered and evaporated to dryness, then the residues were dissolved with $1 \mathrm{~mL}$ of $\mathrm{MeOH}$ and $14 \mathrm{~mL}$ of $\mathrm{H}_{2} \mathrm{O}$, adjusted to $\mathrm{pH} 3.5$ by $\mathrm{HCl}$.

The obtained extract was then purified by SPE using a solid phase extraction vacuum station and a reverse-phase octadecyl (C18, $6 \mathrm{~mL}, 500 \mathrm{mg})$ column (BAKERBOND spe-12G system, J.T. Baker Inc., Deventer, Netherlands). A C18 column was conditioned with $6 \mathrm{~mL} \mathrm{MeOH}$, followed by $6 \mathrm{~mL}$ of $\mathrm{H}_{2} \mathrm{O}(\mathrm{pH} 3.5)$ acidified by $\mathrm{HCl}$. Then, sample extract was passed through the sorbent at a flow rate of approximately $1 \mathrm{~mL} / \mathrm{min}$ and the solid phase was air-dried for $2 \mathrm{~min}$. The analytes were eluted with $6 \mathrm{~mL} \mathrm{MeOH}$ and the eluates were evaporated to dryness. Then, the residues were dissolved with $1 \mathrm{~mL}$ of $\mathrm{MeOH}$ and samples were filtered through a $0.45-\mu \mathrm{m}$ PES membrane. Finally, $5 \mu \mathrm{L}$ of the solution was injected into the UHPLC-MS/MS system. The extraction procedure was performed in triplicate for each sample.

In addition to the tested SLE-SPE procedures, polyphenol extraction efficiency was evaluated using the QuEChERS technique. For this purpose, a salt mixture, $4 \mathrm{~g} \mathrm{MgSO}_{4}, 1 \mathrm{~g}$ $\mathrm{NaCl}, 1 \mathrm{~g}$ trisodium citrate dihydrate, and $0.5 \mathrm{~g}$ disodium hydrogen citrate sesquehydrate were filled in a 50-mL PTFE centrifuge tube. Then, $10 \mathrm{~mL}$ or $20 \mathrm{~mL}$ of $1 \% \mathrm{FA}$ in $\mathrm{ACN}$ and homogenized plant sample (2.5-5.0 g) were added into the tube. The mixture was shaken vigorously for $10 \mathrm{~s}$, vortexed for $1 \mathrm{~min}$, and then centrifuged for $5 \mathrm{~min}$ at $25.2 \times \mathrm{g}$. A $2-3-\mathrm{mL}$ aliquot from the upper part of the extract was transferred into a $15-\mathrm{mL}$ microcentrifuge tube containing $150 \mathrm{mg}$ PSA, $45 \mathrm{mg}$ $\mathrm{GCB}$, and $855 \mathrm{mg} \mathrm{MgSO}_{4}$ (for highly pigmented fruits and vegetables). The mixture was then shaken, vortexed, and centrifuged for $5 \mathrm{~min}$ at $15.4 \times \mathrm{g}$. The harvested $\mathrm{ACN}$ extract was then filtered using a $0.45-\mu \mathrm{m}$ PES filter before UHPLC-MS/ MS analysis.

\section{Instrumentation and UHPLC-MS/MS Conditions}

The UHPLC-MS/MS analyzes were performed by using a triple quadrupole mass spectrometer with a turbo ion spray interface (API 4500, Applied Biosystems, USA) coupled to a Dionex UHPLC liquid chromatography system (Dionex Corporation, Sunnyvale, CA, USA) equipped with an UltiMate 3000 RS 
(Rapid Separation) pump, an UltiMate 3000 autosampler, an UltiMate 3000 column compartment with a thermostable column area, and an UltiMate 3000 variable wavelength detector. Both systems and data treatment were controlled by the Analyst 1.5.1 software (Applied Biosystems, USA).

The optimum condition for the separation of polyphenols using a Zorbax Eclipse XDB-C18 column $(50 \times 2.1 \mathrm{~mm}$, $1.8 \mu \mathrm{m}$, Agilent Technologies, USA) was obtained with the mobile phase: $0.1 \% v / v$ FA in $\mathrm{H}_{2} \mathrm{O}$ (solvent A) and $\mathrm{ACN}$ (solvent B). The UHPLC gradient program used was as follows: (1) mobile phase A was set to $95 \%$ at $0 \mathrm{~min}$, (2) a linear gradient was dropped to $40 \% \mathrm{~A}$ in $8.0 \mathrm{~min}$, (3) mobile phase A was ramped to $95 \%$ again in $0.1 \mathrm{~min}$, and (4) from 8.1 to 10 min, mobile phase A was maintained at $95 \%$. The mobile phase flow rate was $0.5 \mathrm{~mL} / \mathrm{min}$, the injection volume was $5 \mu \mathrm{L}$, and the column temperature was maintained at $30^{\circ} \mathrm{C}$. The total run time was 10 min (Fig. 1).

Electrospray ionization (ESI) conditions in negative mode were first tested with direct infusion into the mass spectrometer to select the precursor and the product ions resulting from fragmentation, declustering potential (DP), collision energy (CE), entrance potential (EP), and collision cell exit potential (CXP) for each polyphenol (Table S1, Supplementary Material). This study was conducted by direct infusion of standard solutions at $10 \mathrm{ng} / \mathrm{mL}$ of flavonoids and phenolic acids at a flow rate of $10 \mu \mathrm{L} / \mathrm{min}$. Flow injection analysis (FIA) was used to optimize capillary voltage, curtain and nebulizer gas flow rates, and source temperature. The experiments were conducted at a mobile phase flow rate (solvent $\mathrm{A} /$ solvent $\mathrm{B}, 1: 1 \mathrm{v} / \mathrm{v}$ ) of $0.5 \mathrm{~mL} / \mathrm{min}$. The following settings were also applied to the turbo ion spray source: capillary voltage (IS), $-4500 \mathrm{~V}$; temperature (TEM), $500{ }^{\circ} \mathrm{C}$; nebulizer gas (GS1), 60 psi; turbo-gas (GS2), 50 psi; curtain gas (CUR), 20 psi; and collision activated dissociation gas (CAD), 4 psi. The polyphenols were evaluated employing the selected reaction monitoring (SRM) mode with a dwell time of $50 \mathrm{~ms}$. The most intense transition was used for quantification and the other transition was used for confirmation.

\section{Method Validation}

The established chromatographic method was evaluated for calibration curve linearity, limit of quantification (LOQ), intra- and inter-day precision and accuracy, recovery, stability, dilution integrity, and carry-over. The full description was placed in the Supplementary Material.

The linearity of the calibration curve was evaluated by analyzing polyphenol standard solutions in $\mathrm{MeOH}$ at ten concentrations ranging from 0.4 to $1000 \mathrm{ng} / \mathrm{mL}$. The LLOQ was defined as the lowest amount of analyte which could be quantified reliably, while complying with the criteria for accuracy and precision. Precision, accuracy, recovery, matrix effect, and stability were determined for the three QC levels (LQC $1 \mathrm{ng} / \mathrm{mL}$, MQC from 40 to $300 \mathrm{ng} / \mathrm{mL}$, and HQC from 80 to $800 \mathrm{ng} / \mathrm{mL}$ ). According to the guidelines matrix effect was determined by comparing the peak areas obtained from blank extract spiked with the analytes to those of pure standard solutions containing the same amount of the analytes. QC sample stability analyzes were performed at $2-8{ }^{\circ} \mathrm{C}$ for the short ( 7 days) and long term (28 days) and the 24-h stabilities were measured in standard solutions at a UHPLC-MS/MS autosampler temperature of $10{ }^{\circ} \mathrm{C}$. Dilution integrity was studied after tenfold dilution of samples spiked with flavonoids and phenolic acids with $\mathrm{MeOH}$. Methanol, which did not contain any analytes or internal standards, was injected after the ULOQ samples to investigate the carry-over of this method in each validation batch.

\section{Results and Discussion}

\section{SLE-SPE Method Development}

The effects of organic and aqueous solvents on the content of flavonoids and phenolic acids determined in lucerne, goldenrod, buckwheat, lavender, phacelia, and licorice were studied using the SLE extraction method. Table S2 (Supplementary Material) summarizes the content of each of the identified
Fig. 1 UHPLC-MS/MS chromatogram of a standard solution containing the analyzed polyphenols and IS

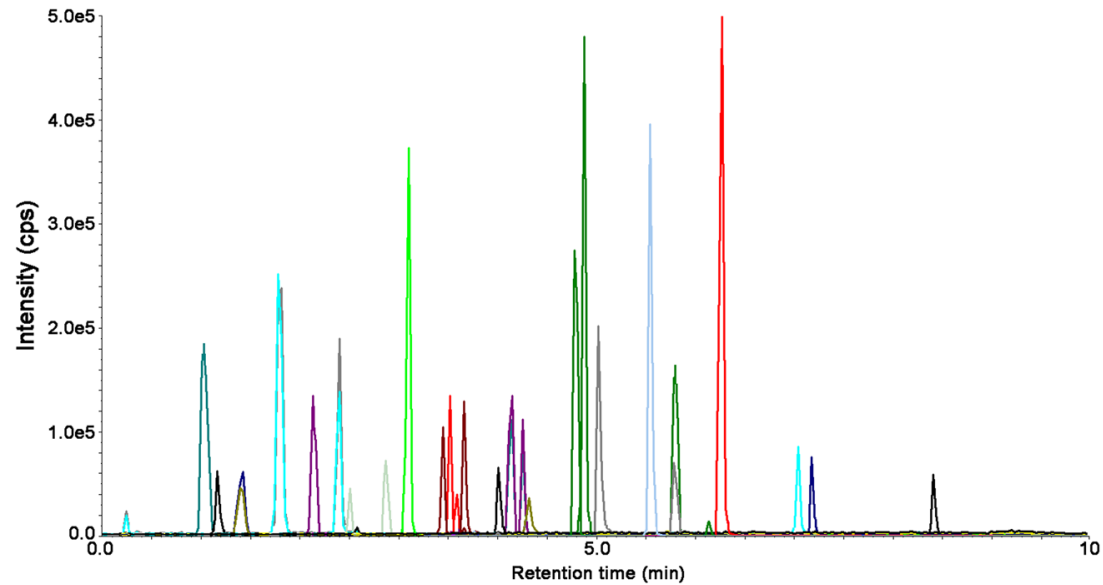


compounds after eight different extraction procedures (ST1ST8) and results for selected compounds are shown in Fig. 2.
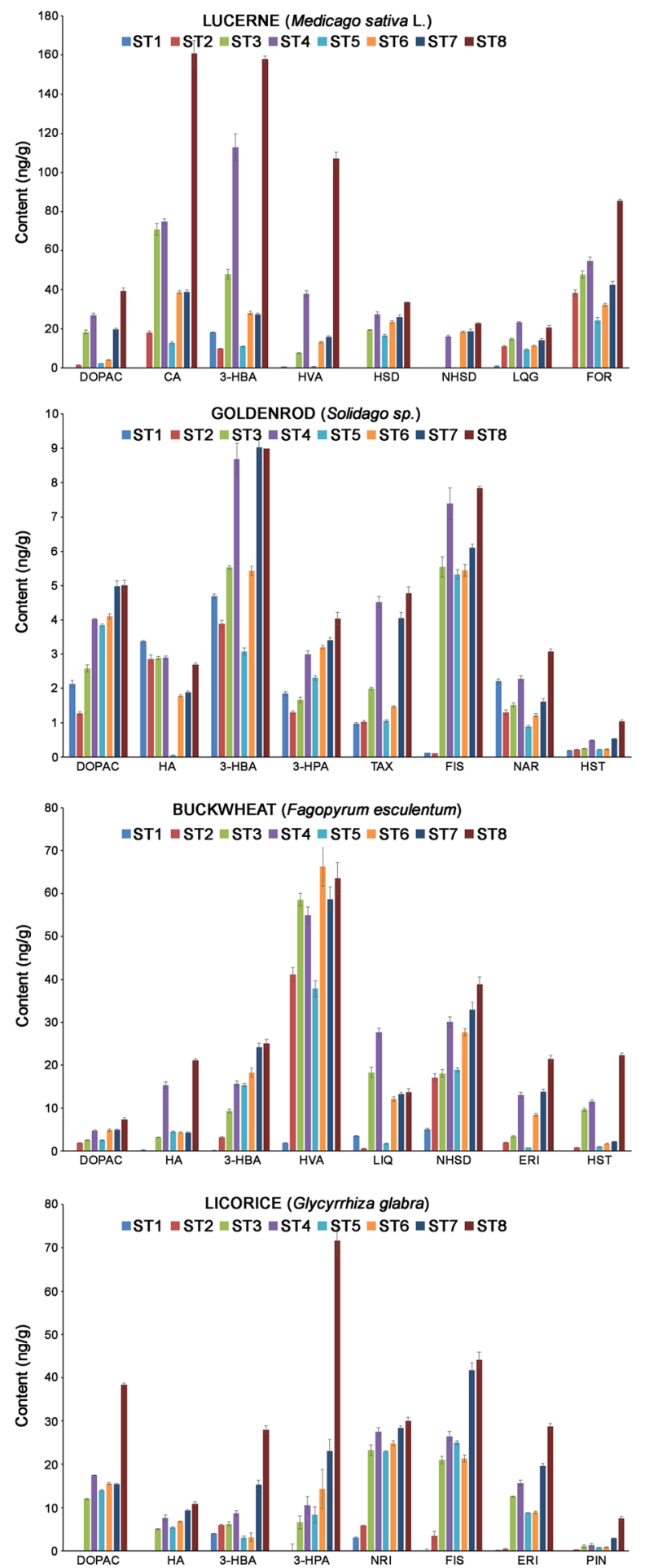

Fig. 2 Effect of the SLE extraction conditions on the peak area of selected polyphenols determined in four different plant materials $\left(\mathrm{ST} 1: \mathrm{H}_{2} \mathrm{O}\right.$, shaking for $5 \mathrm{~h}$; ST2: mixture $\mathrm{H}_{2} \mathrm{O} / \mathrm{EtOH}(1: 1 ; v / v)$, shaking for $2 \mathrm{~h}$; ST3: mixture $\mathrm{H}_{2} \mathrm{O} / \mathrm{EtOH}(1: 1 ; v / v)$, shaking for $5 \mathrm{~h}$; ST4: EtOH, shaking for $5 \mathrm{~h}$; ST5: mixture $\mathrm{H}_{2} \mathrm{O} / \mathrm{MeOH}(1: 1 ; v / v)$, shaking for $2 \mathrm{~h}$; ST6: mixture $\mathrm{H}_{2} \mathrm{O} / \mathrm{MeOH}(1: 1 ; v / v)$, shaking for $2 \mathrm{~h}$ two times; ST7: mixture $\mathrm{H}_{2} \mathrm{O}$ / $\mathrm{MeOH}(1: 1 ; v / v)$, shaking for $5 \mathrm{~h}$; ST8: $\mathrm{MeOH}$, shaking for $5 \mathrm{~h}$
The content of polyphenols varied in response to the extraction solvents and extraction times. For most of the studied compounds, $\mathrm{MeOH}$ (ST8) and EtOH (ST4) extracts of all plant materials had approximately a few times higher values of polyphenols and phenolic acids compared to $\mathrm{H}_{2} \mathrm{O}$ (ST1) and a mixture of $\mathrm{H}_{2} \mathrm{O} / \mathrm{EtOH}(1: 1 ; v / v)(\mathrm{ST} 5)$ or $\mathrm{H}_{2} \mathrm{O} / \mathrm{MeOH}$ $(1: 1 ; v / v)(\mathrm{ST} 7)$ extracts. The mean content of studied polyphenol content increased from $207 \mathrm{ng} / \mathrm{g}$, when the extractions were performed with $\mathrm{H}_{2} \mathrm{O}$ (ST1) to $5566 \mathrm{ng} / \mathrm{g}$ (for licorice), when extractions were performed with $\mathrm{MeOH}$ (ST8). Also increases in the extraction yields of selected analytes were obtained when EtOH (mean amount for example for licorice was $1581 \mathrm{ng} / \mathrm{g}$ ) was used as an extraction solvent (ST4). Intermediate mean amounts $(2980 \mathrm{ng} / \mathrm{g}$ and $2659 \mathrm{ng} / \mathrm{g}$, for licorice) of studied polyphenols were observed after the use of the $\mathrm{H}_{2} \mathrm{O} / \mathrm{MeOH}(1: 1 ; v / v)(\mathrm{ST} 7)$ and $\mathrm{H}_{2} \mathrm{O} / \mathrm{EtOH}(1: 1 ; v / v)$ mixtures (ST5), respectively.

The solubility of polyphenols selected in this study was the highest in $\mathrm{MeOH}$, a little lower in ethanol and the mixture of $\mathrm{H}_{2} \mathrm{O} / \mathrm{MeOH}(1: 1 ; v / v)$ or $\mathrm{H}_{2} \mathrm{O} / \mathrm{EtOH}(1: 1 ; v / v)$, and the lowest in $\mathrm{H}_{2} \mathrm{O} . \mathrm{MeOH}$ showed slightly better characteristics as a solvent for polyphenols and phenolic compounds than $\mathrm{EtOH}$, but the differences were not great, so $\mathrm{EtOH}$ is the more appropriate solvent for use in the food industry.

The content of polyphenols in all plant material extracts increased with extraction times over $5 \mathrm{~h}$. Moreover, two extraction cycles using the $\mathrm{H}_{2} \mathrm{O} / \mathrm{MeOH}(1: 1 ; v / v)$ mixture (ST6) improved the extraction efficiency of polyphenol compounds from plant materials compared to one extraction cycle with the same solvent (ST5). On the other hand, the results obtained for the one-step batch extraction mode using $\mathrm{H}_{2} \mathrm{O} / \mathrm{MeOH}(1: 1$; $v / v)$ for $5 \mathrm{~h}$ (ST7) and in the two-step batch extraction mode using the same mixture two times over $2 \mathrm{~h}$ (ST6) were very similar.

A significant difference was also observed between the contents obtained by the above methods from each of studied plant materials. The difference between extraction yields obtained by the eight methods depended on the raw material analyzed. This remained true, no matter which solvent was used. As shown above, the maximum contents of all the polyphenols were obtained using methanol as the extraction solvent. But, the correlations obtained for the materials were different. Variation in the contents of various extracts is attributed to polarities of different compounds present in the plants and such differences have been reported in the literature (Abarca-Vargas et al. 2016).

Additionally, to achieve better analyte extraction, QuEChERS methods were tested. PSA and GCB were used to remove interferences and pigments. Trials using QuEChERS proved to be less efficient than SLE-SPE extraction for all of the flavonoids and phenolic acids. Some of the compounds (e.g., 3,4-HPPA, 3-HPA, DOPAC, HVA, $\alpha$-HPA, and NRI) were not detected after application of QuEChERS 
Table 1 Content of phenolic acids and flavonoids determined in plant materials

\begin{tabular}{|c|c|c|c|c|c|c|c|c|c|c|c|c|c|}
\hline \multirow[t]{4}{*}{ Compound } & \multicolumn{13}{|c|}{ Content (ng/g) } \\
\hline & \multicolumn{13}{|c|}{$\mathrm{SD}(\mathrm{ng} / \mathrm{g})$} \\
\hline & \multicolumn{3}{|l|}{ Lucerne } & \multicolumn{3}{|c|}{ Goldenrod } & \multicolumn{4}{|l|}{ Phacelia } & \multirow{2}{*}{$\begin{array}{l}\text { Buckwheat } \\
\text { Whole plant }\end{array}$} & \multirow{2}{*}{$\begin{array}{l}\text { Liquorice } \\
\text { Whole plant }\end{array}$} & \multirow{2}{*}{$\begin{array}{l}\text { Lavender } \\
\text { Whole plant }\end{array}$} \\
\hline & Flowers & Leaves & Stalk & Flowers & Leaves & Stalk & Flowers & Leaves & Stalk & Root & & & \\
\hline \multicolumn{14}{|l|}{ Phenolic acids } \\
\hline \multirow[t]{2}{*}{ 3,4-DHBA } & 1808 & 569.1 & 158.1 & 521.7 & 1182 & 743.5 & 347.5 & 230.2 & 212.9 & 211.9 & 4241 & 720.4 & 300.9 \\
\hline & 63.2 & 15.3 & 4.5 & 27.1 & 36.6 & 6.6 & 20.8 & 9.7 & 7.9 & 6.3 & 265 & 31.1 & 6.3 \\
\hline \multirow[t]{2}{*}{$\alpha$-HPA } & ND & ND & ND & ND & ND & ND & ND & ND & ND & ND & ND & ND & ND \\
\hline & ND & ND & ND & ND & ND & ND & ND & ND & ND & ND & ND & ND & ND \\
\hline \multirow[t]{2}{*}{ DOPAC } & 7.0 & 5.6 & 0.17 & 0.22 & NQ & NQ & 868.9 & 1956 & 1199 & 380.6 & 7.4 & 38.8 & 7.4 \\
\hline & 0.1 & 0.2 & 0.01 & 0.01 & NQ & NQ & 24.9 & 38.7 & 65.5 & 16.5 & 0.2 & 0.5 & 0.2 \\
\hline \multirow[t]{2}{*}{ 4-HBA } & 8313 & 3307 & 2163 & 702.3 & 1423 & 115.2 & 4784 & 3915 & 3809 & 4049 & 1241 & 2156 & 1578 \\
\hline & 214 & 58.6 & 61.6 & 29.0 & 55.0 & 4.58 & 137 & 57.5 & 92.9 & 191 & 47.0 & 97.4 & 16.4 \\
\hline \multirow[t]{2}{*}{ CA } & 1675 & 178.5 & 42.8 & 870.3 & 1346 & 557.9 & 404.1 & 811.9 & 873.0 & 1444 & 193.0 & 108.1 & 584.9 \\
\hline & 54.4 & 3.8 & 1.3 & 39.5 & 37.8 & 18.8 & 22.7 & 29.9 & 34.5 & 78.8 & 2.0 & 2.9 & 30.6 \\
\hline \multirow[t]{2}{*}{ HA } & 4.5 & 3.8 & 0.89 & 0.75 & 0.42 & 0.33 & 0.80 & 27.1 & 0.76 & 0.73 & 21.0 & 11.0 & 22.0 \\
\hline & 0.2 & 0.1 & 0.03 & 0.04 & 0.01 & 0.01 & 0.03 & 0.5 & 0.03 & 0.03 & 0.5 & 0.6 & 1.4 \\
\hline \multirow[t]{2}{*}{ 3-HBA } & 64.5 & 169.4 & 172.8 & 1.73 & 5.1 & 0.28 & 21.6 & 0.34 & 0.27 & 2.47 & 25.1 & 28.2 & 18.1 \\
\hline & 2.7 & 9.2 & 4.7 & 0.03 & 0.2 & 0.01 & 0.7 & 0.01 & 0.01 & 0.05 & 1.0 & 1.5 & 0.7 \\
\hline \multirow[t]{2}{*}{ 3-HPA } & 3.5 & 4.42 & 11.8 & 0.27 & 0.24 & NQ & 7.9 & 1.37 & 0.20 & 0.22 & 207.8 & 72.3 & 24.0 \\
\hline & 0.1 & 0.08 & 0.4 & 0.01 & 0.01 & NQ & 0.1 & 0.06 & 0.01 & 0.01 & 14.6 & 2.0 & 0.7 \\
\hline HVA & 48.0 & 24.7 & 34.8 & 1.53 & 33.0 & 17.1 & 24.1 & 13.0 & 25.0 & 43.5 & 63.6 & 821.2 & 65.1 \\
\hline & 0.8 & 0.7 & 1.6 & 0.06 & 0.8 & 0.6 & 0.3 & 0.3 & 0.6 & 0.6 & 3.8 & 33.9 & 1.6 \\
\hline 3,4-НРРА & 2397 & 632.8 & 446.4 & 265.7 & 214.7 & 79.9 & 77.9 & 161.5 & 141.4 & 237.2 & 257.1 & 118,535 & 558.3 \\
\hline & 93.7 & 36.3 & 17.2 & 12.6 & 6.2 & 2.0 & 2.9 & 2.5 & 2.0 & 2.3 & 10.2 & 3733 & 11.3 \\
\hline $\mathrm{p}-\mathrm{CA}$ & 2160 & 781.7 & 544.5 & 365.3 & 264.7 & 104.3 & 173.4 & 297.9 & 11,778 & 324.8 & 396.1 & 703.8 & 520.3 \\
\hline & 58.5 & 7.6 & 23.7 & 19.9 & 4.0 & 1.1 & 9.3 & 8.1 & 233 & 8.7 & 16.5 & 13.9 & 26.7 \\
\hline FA & 5496 & 1332 & 462.1 & 919.8 & 519.3 & 611.1 & 385.6 & 610.1 & 608.1 & 823.8 & 158.7 & 166.2 & 379.9 \\
\hline & 112 & 41.4 & 4.0 & 13.9 & 12.3 & 33.0 & 13.8 & 23.6 & 6.5 & 12.8 & 6.3 & 4.7 & 12.0 \\
\hline BA & 7086 & 10,000 & 3717 & 280.6 & 871.2 & 195.9 & 648.5 & 360.9 & 170.9 & 197.3 & 665.9 & 3085 & 687.3 \\
\hline & 225 & 417 & 47.2 & 5.5 & 15.2 & 3.4 & 19.3 & 13.3 & 4.2 & 1.9 & 14.5 & 33.3 & 20.4 \\
\hline Flavonoids & & & & & & & & & & & & & \\
\hline ERC & 0.24 & 0.41 & NQ & 0.07 & NQ & NQ & NQ & 3.09 & NQ & NQ & 9.6 & NQ & 4.3 \\
\hline & 0.01 & 0.01 & NQ & 0.01 & NQ & NQ & NQ & 0.03 & NQ & NQ & 0.5 & NQ & 0.1 \\
\hline LIQ & 13.5 & 0.59 & 1.28 & ND & ND & 0.47 & ND & ND & ND & NQ & 13.8 & 1359 & 2.21 \\
\hline & 0.4 & 0.01 & 0.04 & ND & ND & 0.02 & ND & ND & ND & NQ & 0.2 & 21.2 & 0.02 \\
\hline RUT & 147.6 & 148.4 & 59.0 & 17,384 & 23,523 & 6394 & 13,922 & 10,296 & 1129 & 2336 & 7521 & 2.19 & 282.9 \\
\hline & 1.8 & 4.1 & 2.3 & 615 & 597 & 228 & 414 & 351 & 44.9 & 78.9 & 130 & 0.08 & 6.1 \\
\hline TAX & 101.3 & 45.5 & 43.6 & 0.73 & 2.62 & 0.30 & 0.79 & 5.9 & 1.59 & 4.0 & 40.4 & 1.05 & 3.88 \\
\hline & 3.2 & 0.9 & 1.6 & 0.03 & 0.05 & 0.01 & 0.03 & 0.1 & 0.04 & 0.2 & 1.9 & 0.03 & 0.04 \\
\hline NRI & 15.4 & 5.8 & 8.2 & 3.9 & 3.18 & 3.1 & 7.8 & 3.6 & 7.6 & 4.75 & 8.9 & 30.3 & 13.9 \\
\hline & 0.5 & 0.1 & 0.5 & 0.2 & 0.08 & 0.1 & 0.5 & 0.2 & 0.3 & 0.06 & 0.2 & 0.9 & 0.4 \\
\hline NARG & 0.75 & 0.43 & 0.30 & NQ & ND & 0.22 & 0.78 & NQ & 0.31 & NQ & 0.51 & 2.7 & 0.87 \\
\hline & 0.03 & 0.01 & 0.01 & NQ & ND & 0.01 & 0.02 & NQ & 0.02 & NQ & 0.01 & 0.1 & 0.02 \\
\hline HSD & 29.9 & 8.9 & 19.5 & 0.26 & 0.25 & 63.3 & 93.1 & 66.5 & 57.6 & 0.97 & 1227 & 7.6 & 23.0 \\
\hline & 0.2 & 0.3 & 0.3 & 0.01 & 0.02 & 2.6 & 2.9 & 1.7 & 2.8 & 0.05 & 29.9 & 0.3 & 0.9 \\
\hline NHSD & 12.3 & 11.5 & 10.5 & 0.15 & 0.13 & 33.1 & 62.1 & 22.2 & 34.1 & 0.52 & 38.8 & 5.5 & 32.1 \\
\hline & 0.1 & 0.3 & 0.2 & 0.01 & 0.01 & 1.5 & 2.4 & 0.9 & 0.2 & 0.01 & 1.8 & 0.3 & 1.6 \\
\hline
\end{tabular}


Table 1 (continued)

\begin{tabular}{|c|c|c|c|c|c|c|c|c|c|c|c|c|c|}
\hline \multirow[t]{4}{*}{ Compound } & \multicolumn{13}{|c|}{ Content (ng/g) } \\
\hline & \multicolumn{13}{|c|}{$\mathrm{SD}(\mathrm{ng} / \mathrm{g})$} \\
\hline & \multicolumn{3}{|l|}{ Lucerne } & \multicolumn{3}{|c|}{ Goldenrod } & \multicolumn{4}{|l|}{ Phacelia } & \multirow{2}{*}{$\begin{array}{l}\text { Buckwheat } \\
\text { Whole plant }\end{array}$} & \multirow{2}{*}{$\begin{array}{l}\text { Liquorice } \\
\text { Whole plant }\end{array}$} & \multirow{2}{*}{$\begin{array}{l}\text { Lavender } \\
\text { Whole plant }\end{array}$} \\
\hline & Flowers & Leaves & Stalk & Flowers & Leaves & Stalk & Flowers & Leaves & Stalk & Root & & & \\
\hline \multirow[t]{2}{*}{ FIS } & 5.4 & 1.44 & 0.32 & 5.9 & 0.70 & 0.21 & 14.7 & NQ & NQ & NQ & ND & 44.6 & 0.40 \\
\hline & 0.3 & 0.03 & 0.02 & 0.2 & 0.02 & 0.01 & 0.6 & NQ & NQ & NQ & ND & 0.4 & 0.01 \\
\hline \multirow[t]{2}{*}{ LQG } & 38.6 & 11.4 & 26.7 & ND & NQ & ND & NQ & NQ & ND & ND & 12.3 & 1463 & 0.41 \\
\hline & 1.7 & 0.3 & 0.9 & ND & NQ & ND & NQ & NQ & ND & ND & 0.2 & 40.0 & 0.03 \\
\hline \multirow[t]{2}{*}{ ERI } & 2.9 & 0.76 & 2.8 & 1.14 & 6.1 & 0.25 & 21.3 & 25.8 & 2.5 & 0.19 & 21.5 & 29.0 & 7.4 \\
\hline & 0.1 & 0.03 & 0.1 & 0.02 & 0.1 & 0.01 & 0.8 & 0.7 & 0.1 & 0.01 & 0.3 & 1.3 & 0.2 \\
\hline \multirow[t]{2}{*}{ QUE } & 1168 & 56.9 & NQ & 1281 & 3363 & NQ & 20.6 & 58.1 & 74.3 & 0.27 & 908.3 & 5.4 & 15.9 \\
\hline & 25.3 & 2.3 & NQ & 11.1 & 104 & NQ & 0.5 & 2.2 & 2.0 & 0.01 & 32.7 & 0.1 & 0.4 \\
\hline \multirow[t]{2}{*}{ NAR } & 16.3 & 6.9 & 0.38 & 0.45 & 1.44 & 0.50 & 1.60 & 1.88 & 0.99 & 1.00 & 146.8 & 474.7 & 398.1 \\
\hline & 0.6 & 0.3 & 0.02 & 0.03 & 0.01 & 0.02 & 0.05 & 0.07 & 0.03 & 0.02 & 4.2 & 5.0 & 15.8 \\
\hline \multirow[t]{2}{*}{ HST } & NQ & 0.18 & NQ & NQ & 24.9 & NQ & 0.16 & 0.67 & NQ & 0.42 & 22.2 & 1.17 & 0.81 \\
\hline & NQ & 0.01 & NQ & NQ & 1.5 & NQ & 0.01 & 0.02 & NQ & 0.02 & 0.8 & 0.03 & 0.01 \\
\hline \multirow[t]{2}{*}{ FOR } & 245.2 & 74.7 & 253.7 & ND & ND & ND & ND & ND & ND & ND & 1.56 & 751.7 & 7.0 \\
\hline & 15.4 & 5.2 & 10.7 & ND & ND & ND & ND & ND & ND & ND & 0.04 & 31.3 & 0.2 \\
\hline \multirow[t]{2}{*}{ PIN } & 0.63 & 0.50 & NQ & 0.45 & 0.68 & NQ & 0.24 & 0.33 & NQ & NQ & 1.98 & 7.6 & 0.91 \\
\hline & 0.02 & 0.03 & NQ & 0.01 & 0.02 & NQ & 0.01 & 0.01 & NQ & NQ & 0.06 & 0.3 & 0.02 \\
\hline \multirow[t]{2}{*}{ GLB } & ND & ND & ND & ND & ND & ND & ND & ND & ND & ND & 186.8 & 25,230 & ND \\
\hline & ND & ND & ND & ND & ND & ND & ND & ND & ND & ND & 5.0 & 393 & ND \\
\hline
\end{tabular}

Each value is the mean of three replications

$S D$ standard deviation, $N D$ not detectable, $N Q$ not quantifiable

procedures for sample preparation in all studied plants. The mean contents of polyphenols were lower than the mean content obtained after application of the ST8 procedure: 2 times lower for lucerne, 40 times lower for buckwheat, 35 times lower for goldenrod, 5 times lower for lavender and licorice, and 15 times lower for lacy phacelia. Based on these results, it can be concluded that a QuEChERS method could not yield satisfactory extraction of all target analytes.

\section{Method Validation}

The full results obtained during method validation were placed in the Supplementary Material.

Linearity for flavonoids and phenolic acids were obtained over different concentration range depending on studied compounds (Table S3). Limits of quantification range from 0.4 to $20 \mathrm{ng} / \mathrm{mL}$. The precision of the method presented RSD values was lower than $9.12 \%$. The intra-day accuracy ranged from 7.54 to $6.92 \%$ and inter-day accuracy ranged from -9.57 to $8.63 \%$ (Table S3). The recoveries of polyphenols were found to be $48.9-97.2 \%$ (Table S3). All analytes and IS kept in different conditions showed a variation lower than $8.47 \%$ at all concentrations (Table S4).

\section{Analysis of Plant Materials}

The SLE-SPE-UHPLC-MS/MS assay method was subsequently applied to the simultaneous determination of the 30 major active polyphenols in the different plants and in different parts of the plants. The results of the quantitative determinations of the flavonoids and phenolic acids are listed in Table 1. The analysis of each sample was replicated three times, i.e., from sample preparation to chromatographic analysis.

Lucerne (Flowers, Leaves, and Stalks) Figure 3 reports MRM chromatograms for selected compounds analyzed in extracts of lucerne flowers, leaves, and stalks. A higher amount of phenolic acids was observed for lucerne leaves (from 3.77 to $10,000 \mathrm{ng} / \mathrm{g}$ ) than for lucerne flowers and stalks (from 3.52 to 8313 and from 0.17 to $3717 \mathrm{ng} / \mathrm{g}$, respectively). The concentration of flavonoids was higher in flowers $(0.24-1168 \mathrm{ng} / \mathrm{g})$ than in leaves and stalks $(0.18-148.4$ and $0.30-253.7 \mathrm{ng} / \mathrm{g})$. The main phenolic acid of lucerne flowers was a 4-HBA component, which was present at the level of $8313 \mathrm{ng} / \mathrm{g}$ dry sample. The content of 4-HBA in the samples of lucerne leaves and stalks was markedly lower (3307 ng/g and $2163 \mathrm{ng} / \mathrm{g}$, 

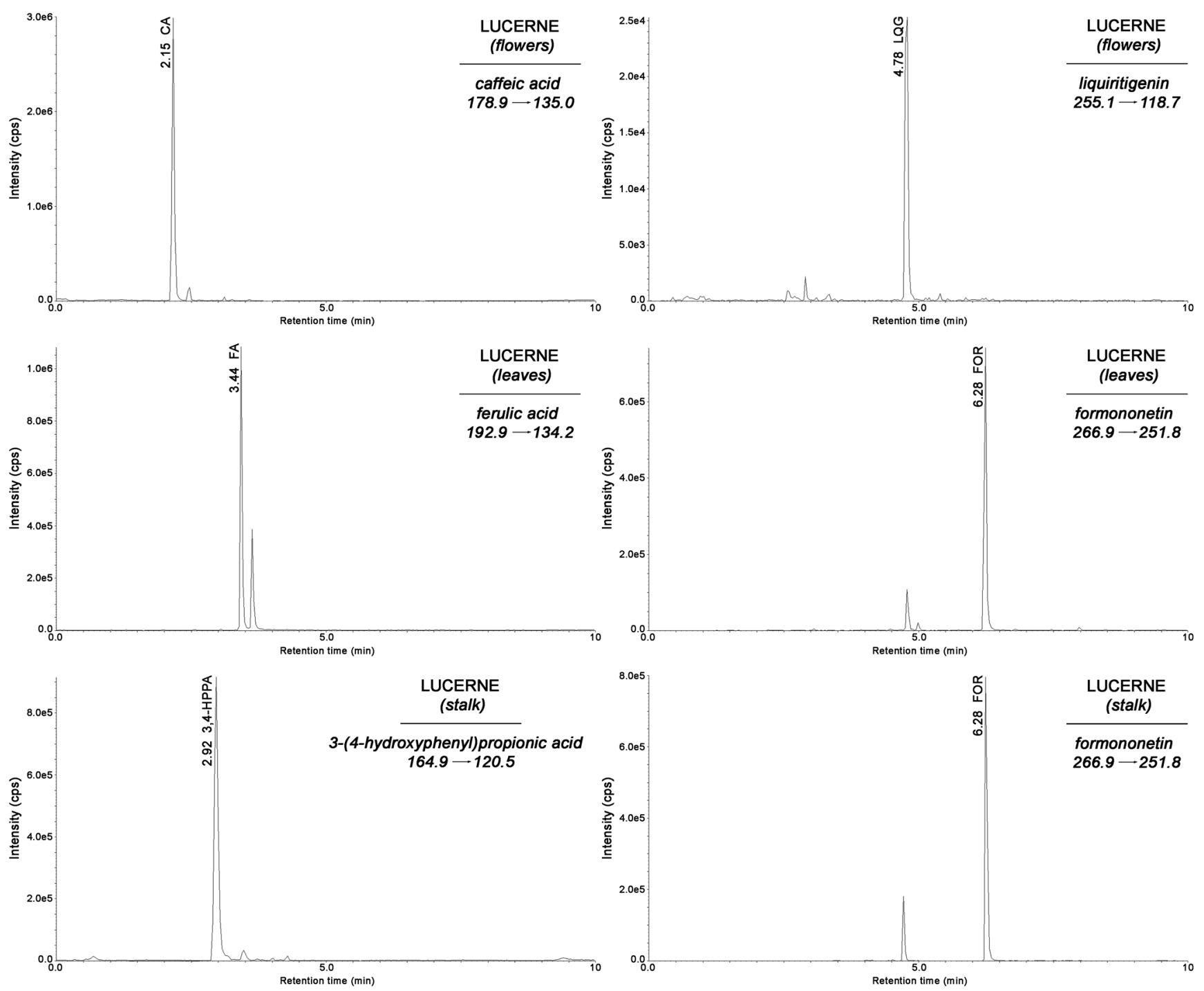

Fig. 3 Representative MRM chromatograms of selected phenolic acids and flavonoids analyzed in extracts of lucerne flowers, leaves, and stalks

respectively). Flowers of lucerne contained a high level of QUE (flavonoid), and these could be used as a new resource of this bioactive compound. $\alpha$-HPA and GLB were not detected in all analyzed extracts of lucerne; HST was not quantified in extracts of flowers and stalk; and ERC, QUE, and PIN were not quantified in lucerne stalks (<LOQ).

Goldenrod (Flowers, Leaves, and Stalks) UHPLC-MS/MS profiles of the flowers, leaves, and stalk are similar, indicating that they contained the same phenolic acids and flavonoids and only the amounts are slightly different (Fig. 4). Extracts of goldenrod leaves showed the highest concentrations of the determined polyphenols (0.13$23,523 \mathrm{ng} / \mathrm{g})$ compared to flowers $(0.07-17,384 \mathrm{ng} / \mathrm{g})$ and stalks (0.21-6394 ng/g). When exploring the phenolic acids present in goldenrod, 4-HBA was the main compound in leaves (1423 ng/g), while FA was most present in the flowers $(919.8 \mathrm{ng} / \mathrm{g})$ and stalks $(611.1 \mathrm{ng} / \mathrm{g})$.
DOPAC and ERC were missing in leaves and stalks and were present at a low amount in the flowers $(0.22$ and $0.07 \mathrm{ng} / \mathrm{g}$, respectively). One phenolic acid ( $\alpha$-HPA) and three flavonoids (LQG, FOR, and GLB) were not detected or quantified in the whole extracts of goldenrod.

Phacelia (Flowers, Leaves, Stalks, and Roots) RUT (flavonoid) and 4-HBA (phenolic acid) were predominant in all investigated phacelia samples analyzed using the UHPLC-MS/MS method, but there was no significant difference between their content in flowers and leaves. The highest flavonoid content was found in the phacelia flowers (from 0.16 to $13,922 \mathrm{ng} / \mathrm{g}$ ). The compounds with the highest concentrations in the flowers samples were RUT, followed by HSD and NHSD. Also, a higher phenolic acid content was observed in the flowers of phacelia (from 0.80 to $4784 \mathrm{ng} / \mathrm{g}$ ). The data obtained for HA, 3-HBA, and 3-HPA mostly indicated lower concentrations 
Fig. 4 Representative chromatograms of all determined polyphenols in an extracts of goldenrod flowers, leaves, and stalks
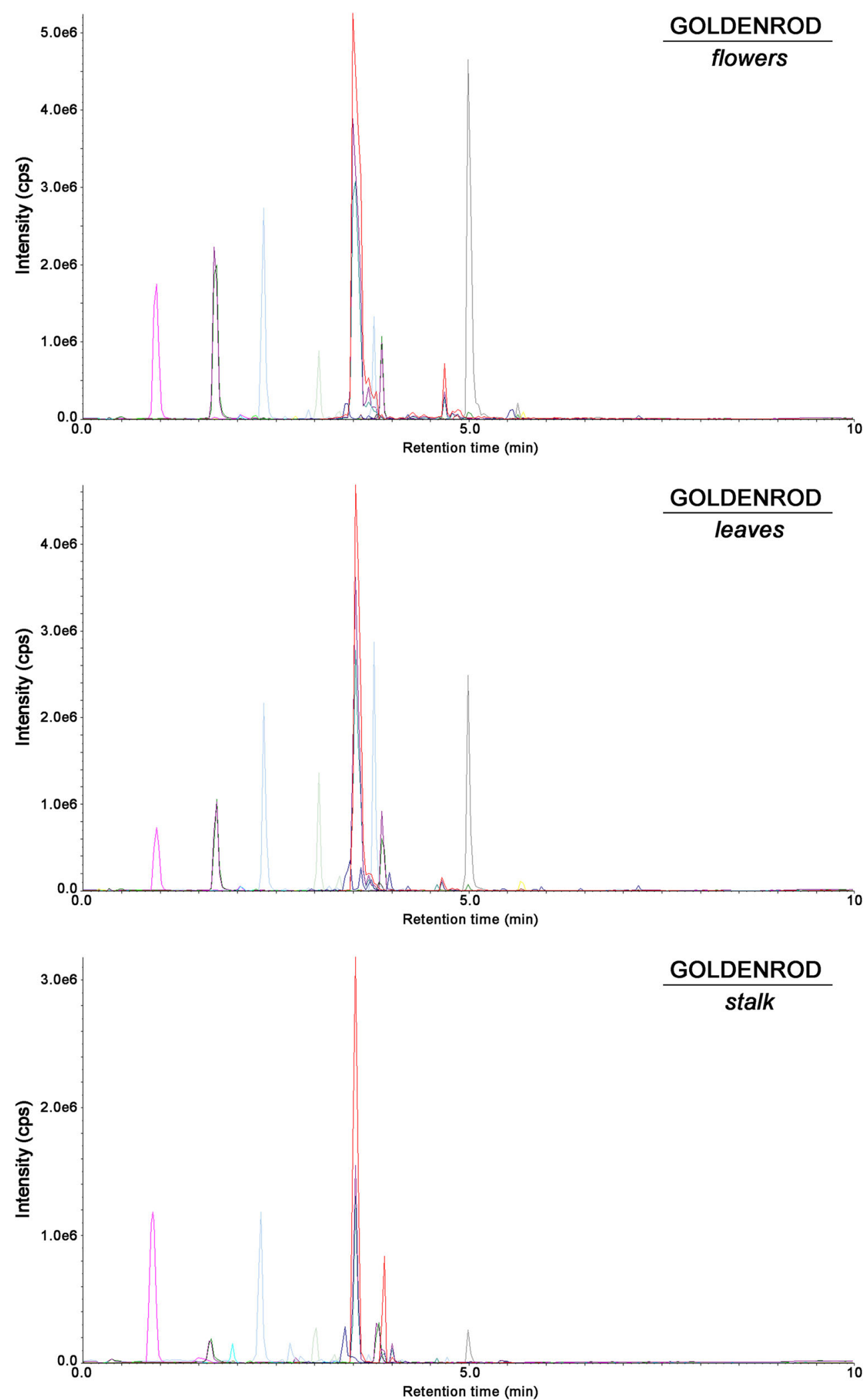

in comparison with other acids. Extracts of phacelia flowers, leaves, and roots presented similar levels of phenolic acids $(0.8-4784 \mathrm{ng} / \mathrm{g}, 0.34-3915 \mathrm{ng} / \mathrm{g}$, and 0.22
4049 ng/g, respectively). Figure 5 shows MRM chromatograms for selected polyphenols obtained after analysis of extracts of phacelia flowers, leaves, stalks, and roots. 

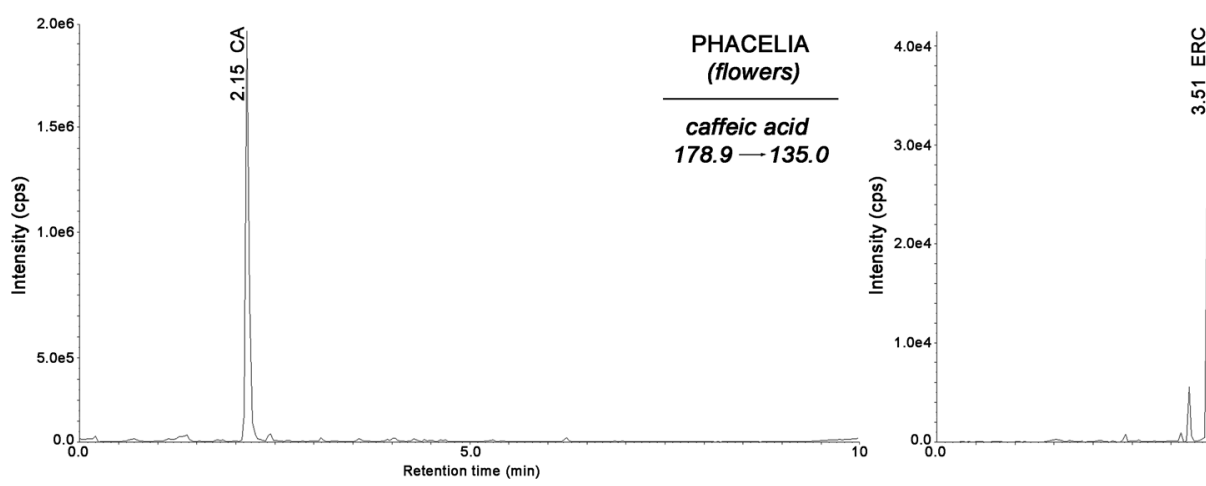

PHACELIA
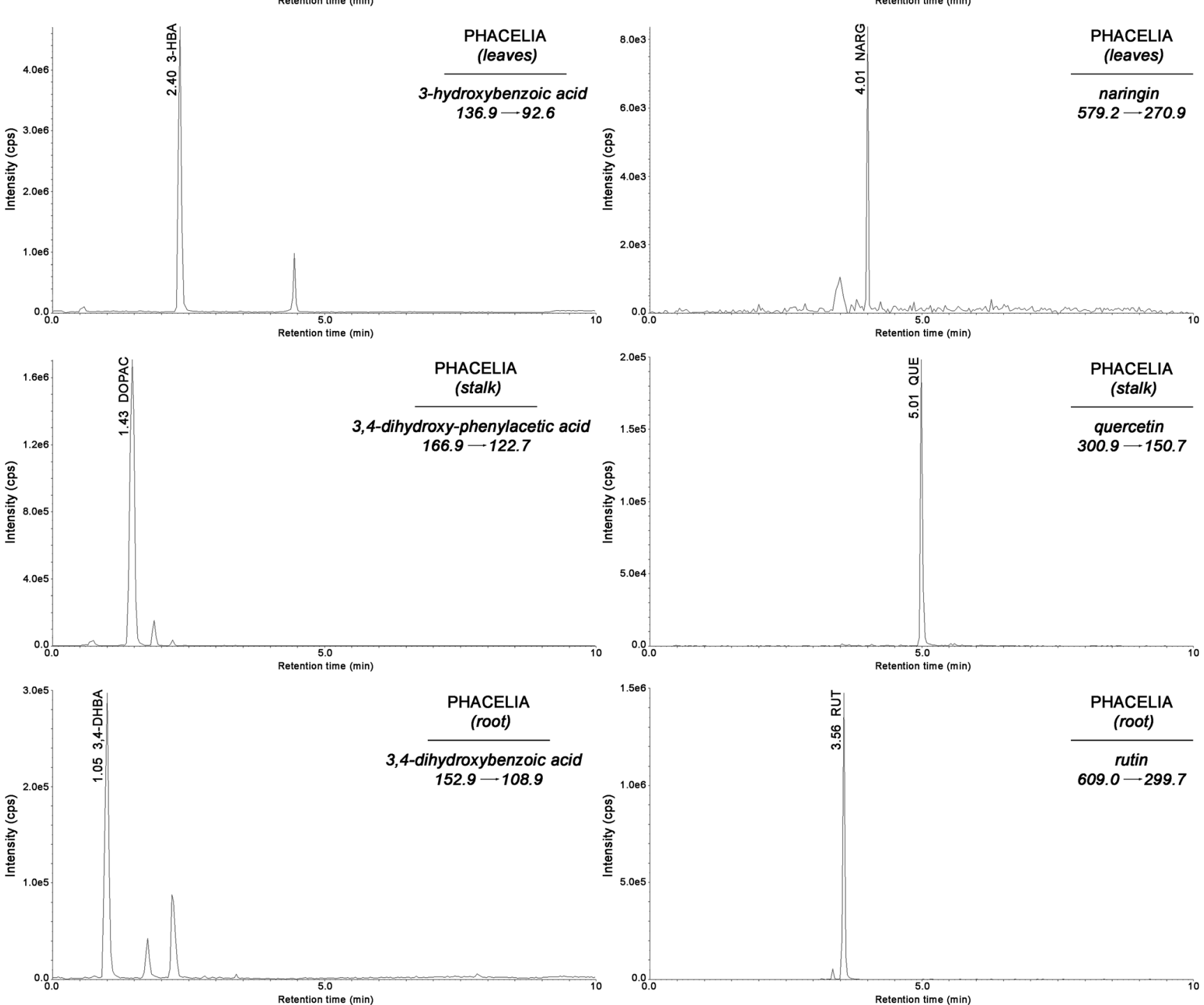

Fig. 5 Representative MRM chromatograms of selected phenolic acids and flavonoids analyzed in extracts of phacelia flowers, leaves, stalks, and roots

Buckwheat According to UHPLC-MS/MS experiments, 27 polyphenols could be detected in the buckwheat, while $\alpha$-HPA and FIS were not present in this plant. The most abundant phenolic acids were 3,4-DHBA (4241 ng/g) and 4-HBA (1241 ng/g) and the most abundant flavonoids were RUT $(7521 \mathrm{ng} / \mathrm{g})$ and QUE $(908.3 \mathrm{ng} / \mathrm{g})$. The amounts of all phenolic acids were in the range from 7.39 to $4241 \mathrm{ng} / \mathrm{g}$. Flavonoids were present at levels from 0.511 to $7521 \mathrm{ng} / \mathrm{g}$.

Licorice The contents of phenolic acids and flavonoids in licorice sample were from 11.04 to $118,535 \mathrm{ng} / \mathrm{g}$ and between 1.047 and $25,230 \mathrm{ng} / \mathrm{g}$, respectively. GLB, a major flavonoid, was present at a higher concentration level $(25,230 \mathrm{ng} / \mathrm{g})$, 
while 3,4-HPPA, another major phenolic acid, was present at the concentration of $118,535 \mathrm{ng} / \mathrm{g}$. ERC and $\alpha$-HPA were not quantified in the analyzed extracts of licorice.

Lavender The results obtained using the proposed UHPLCMS/MS method for phenolic acids varied from 7.38 to $1578 \mathrm{ng} / \mathrm{g}$ and for flavonoids from 0.401 to $398.1 \mathrm{ng} / \mathrm{g}$. The main phenolic acids and flavonoids found in lavender were 4-HBA (1578 ng/g) and NAR (398.1 ng/g), respectively. In lavender samples, $\alpha$-HPA and GLB were not detected.

As a summary of the analysis of different plant materials, it may be conducted that the qualitative and especially quantitative polyphenol profiles in lucerne, goldenrod, phacelia, buckwheat, licorice, and lavender are significantly different. It may be supposed that the pharmacological activities of the studied plants are not equal.
The highest total content of the analyzed polyphenols was found in licorice $(156 \mu \mathrm{g} / \mathrm{g}$ dry sample). The extracts of licorice contain nearly ten times higher levels of phenolic acids and flavonoids in comparison with those of buckwheat (17.6 $\mu \mathrm{g} / \mathrm{g})$, phacelia $(21.9 \mu \mathrm{g} / \mathrm{g})$, and lucerne $(29.1 \mu \mathrm{g} / \mathrm{g})$. The main phenolic constituents of the mentioned plants are also different, depending on the type of plant (Figure 6). The lowest contents of all the target polyphenols were found in lavender $(4.75 \mu \mathrm{g} / \mathrm{g})$. Most of the compounds selected in this study were determined in the extracts of whole plants. Only $\alpha$ HPA was not detected in all analyzed extracts, while GLB was quantified only in buckwheat and licorice. The content of the acids and flavonoids assayed in selected plants was of the same order of magnitude as that given in the literature (Wang and Yang 2007; Sabir et al. 2012).

Determining the amounts of individual polyphenols is important owing to their specific properties. Different phenolic
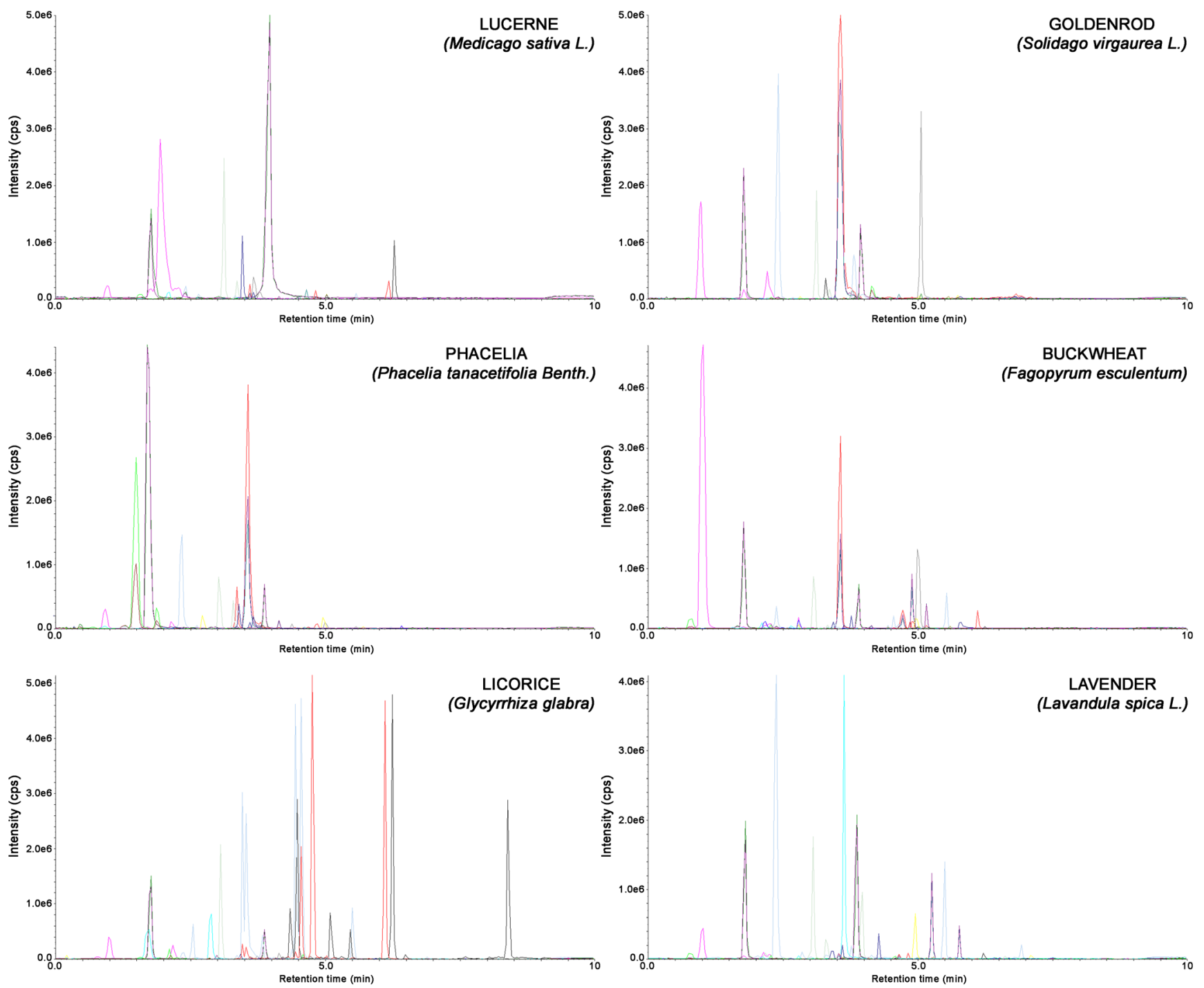

Fig. 6 Representative chromatograms obtained for extracts of lucerne, goldenrod, phacelia, buckwheat, licorice, and lavender using the proposed SLESPE-UHPLC-MS/MS method 
acids and flavonoids have different abilities for scavenging free radicals (Rice-Evans et al. 1996), between them there are differences in stability (Sharma et al. 2015), and they also have different pharmacological activities (Benavente-García et al. 1997). Moreover, identifying individual polyphenols is also important because they can be used as markers to evaluate the authenticity of plant products, even if the composition of cosmetics and dietary supplements is affected by the processing and storage conditions. Since the validated UHPLCMS/MS method allows the identification and quantification of the main polyphenols present in the six plants, it may find application as an important analytical tool for researchers from various industries, with particular emphasis on quality control of cosmetics and dietary supplements.

According to the literature, this is the first study that combines SLE-SPE and UHPLC-MS/MS for the extraction and determination of flavonoids and phenolic acids in six different plants. The total analysis time of the UHPLC protocol was within $10 \mathrm{~min}$, in contrast to the previous HPLC procedures that involved analysis times of 40-100 min (Farag et al. 2012; Liao et al. 2012; Montoro et al. 2011; Verardo et al. 2010). Other non-negligible advantages to our method are simultaneous determination of 30 main flavonoids and phenolic acids. In addition, the SLE-SPE-UHPLC-MS/MS procedure provided higher sensitivity and selectivity in comparison with the HPLC-DAD method (Kreft et al. 2006; Wang and Yang 2007).

\section{Conclusion}

In this paper, an efficient method for simultaneous determination of 30 polyphenols in plants has been developed for the first time using UHPLC-MS/MS based on SLE and SPE extractions.

Based on our results, it can be stated that the extraction solvent significantly affected polyphenol content in extracts. Both phenolic acids and flavonoids were isolated from plants by extraction using methanol and purification with a $\mathrm{C} 18$ reversed-phase SPE cartridge. For the most compounds, good recoveries and RSDs $(<10 \%)$ were obtained, and only for $\alpha$ HPA, DOPAC, and LIQ, the recoveries were lower. Limits of quantification range from 0.4 to $20 \mathrm{ng} / \mathrm{mL}$.

The developed procedure demonstrated to be effective for quantifying polyphenols in very complex matrixes such as lucerne, licorice, goldenrod, buckwheat, phacelia, and lavender. The main phenolic acids in the studied plants have been found to be 3,4-HPPA, 4-HBA, and 3,4-DHBA. QUE, RUT, GLB, and NAR are the major flavonoids detected in the analyzed samples.

This method has already been successfully applied to determine those active components in different parts of the plants or in whole plants. The obtained scientific data can be useful to select plant materials with high nutritional value and the presence of many biologically active ingredients, as well as selecting samples used as a plant biomass and as a components of dietary supplements.

Funding This project was supported by funds from the National Centre for Research and Development (NCBR) within the framework of the Project PLANTARUM (NCBiR, BIOSTRATEG2/298205/9/NCBR/ 2016, Warsaw, Poland). The research was performed with LC-MS/MS equipment purchased within the Silesian BIO-FARMA Project (Poland).

\section{Compliance with Ethical Standards}

Conflict of Interest Sylwia Bajkacz declares that she has no conflict of interest. Irena Baranowska declares that she has no conflict of interest. Bogusław Buszewski declares that he has no conflict of interest. Bartosz Kowalski declares that he has no conflict of interest. Magdalena Ligor declares that she has no conflict of interest.

Ethical Approval This article does not contain any studies with human or animal subjects.

Informed Consent Informed consent was not applicable.

Open Access This article is distributed under the terms of the Creative Commons Attribution 4.0 International License (http:// creativecommons.org/licenses/by/4.0/), which permits unrestricted use, distribution, and reproduction in any medium, provided you give appropriate credit to the original author(s) and the source, provide a link to the Creative Commons license, and indicate if changes were made.

\section{References}

Abarca-Vargas R, Peña Malacara CF, Petricevich VL (2016) Characterization of chemical compounds with antioxidant and cytotoxic activities in Bougainvillea $\mathrm{x}$ buttiana Holttum and Standl, (var. Rose) extracts. Antioxidants 5:1-11

Apáti P, Szentmihályi K, Balázs A, Baumann D, Hamburger M, Kristó TSZ, Szöke E, Kéry Á (2002) HPLC analysis of the flavonoids in pharmaceutical preparations from Canadian goldenrod (Solidago canadensis). Chromatographia 56:S-65-S-68

Areias FM, Valentão P, Andrade PB, Moreira MM, Amaral J, Seabra RM (2000) HPLC/DAD analysis of phenolic compounds from lavender and its application to quality control. J Liq Chromatogr Relat Technol 23:2563-2572

Benavente-García O, Castillo J, Marin FR, Ortuño A, Del Río JA (1997) Uses and properties of Citrus flavonoids. J Agric Food Chem 45: 4505-4515

Chen XJ, Zhao J, Meng Q, Wang YT (2009) Simultaneous determination of five flavonoids in licorice using pressurized liquid extraction and capillary electrochromatography coupled with peak suppression diode array detection. J Chromatogr A 1216:7329-7335

Danila AM, Kotani A, Hakamata H, Kusu F (2007) Epicatechin, and epicatechin gallate in buckwheat Fagopyrum esculentum Moench by micro-high-performance liquid chromatography with electrochemical detection. J Agric Food Chem 55:1139-1143

Farag MA, Huhman DV, Lei Z, Sumner LW (2007) Metabolic profiling and systematic identification of flavonoids and isoflavonoids in roots and cell suspension cultures of Medicago truncatula using HPLC-UV-ESI-MS and GC-MS. Phytochem 68:342-354

Farag MA, Porzel A, Wessjohann LA (2012) Comparative metabolite profiling and fingerprinting of medicinal licorice roots using a 
multiplex approach of GC-MS, LC-MS and 1D NMR techniques. Phytochem 76:60-72

Goławska S, Łukasik I, Kapusta I, Janda B (2010a) Analysis of flavonoids content in alfalfa. Ecol Chem Eng A 17:261-267

Goławska S, Łukasik I, Goławski A, Kapusta I, Janda B (2010b) Alfalfa (Medicago sativa L.) apigenin glycosides and their effect on the pea aphid (Acyrthosiphon pisum). Pol J Environ Stud 19:913-919

Kreft S, Knapp M, Kreft I (1999) Extraction of rutin from buckwheat (Fagopyrum esculentum Moench) seeds and determination by capillary electrophoresis. J Agric Food Chem 47:4649-4652

Kreft I, Fabjan N, Yasumoto K (2006) Rutin content in buckwheat (Fagopyrum esculentum Moench) food materials and products. Food Chem 98:508-512

Liao WC, Lin YH, Chang TM, Huang WY (2012) Identification of two licorice species, Glycyrrhiza uralensis and Glycyrrhiza glabra, based on separation and identification of their bioactive components. Food Chem 132:2188-2193

Marczak Ł, Stobiecki M, Jasiński M, Oleszek W, Kachlicki P (2010) Fragmentation pathways of acylated flavonoid diglucuronides from leaves of Medicago truncatula. Phytochem Anal 21:224-233

Martin LM, Castilho MC, Silveira IM, Abreu JM (2006) Liquid chromatographic validation of a quantitation method for phytoestrogens, biochanin-A, coumestrol, daidzein, formononetin, and genistein, in lucerne. J Liq Chromatogr Relat Technol 29:2875-2884

Montoro P, Maldini M, Russo M, Postorino S, Piacente S, Pizza C (2011) Metabolic profiling of roots of liquorice (Glycyrrhiza glabra) from different geographical areas by ESI/MS/MS and determination of major metabolites by LC-ESI/MS and LC-ESI/MS/MS. J Pharm Biomed Anal 54:535-544

Rice-Evans C, Miller NJ, Paganga G (1996) Structure-antioxidant activity relationships of flavonoids and phenolic acids. Free Radic Biol Med 20:933-956
Sabir SM, Ahmad SD, Hamid A, Khan MQ, Athayde ML, Santos DB, Boligon AA, Rocha JBT (2012) Antioxidant and hepatoprotective activity of ethanolic extract of leaves of Solidago microglossa containing polyphenolic compounds. Food Chem 131:741-747

Shahidi F, Ambigaipalan P (2015) Phenolics and polyphenolics in foods, beverages and spices: antioxidant activity and health effects - a review. J Funct Food 18:820-897

Sharma K, Ko EY, Assefa AD, Ha S, Nile SH, Lee ET, Park SW (2015) Temperature-dependent studies on the total phenolics, flavonoids, antioxidant activities, and sugar content in six onion varieties. JFDA 23:243-252

Siracusa L, Saija A, Cristani M, Cimino F, D'Arrigo M, Trombetta D, Rao F, Ruberto G (2011) Phytocomplexes from liquorice (Glycyrrhiza glabra L.) leaves - chemical characterization and evaluation of their antioxidant, anti-genotoxic and anti-inflammatory activity. Fitoterapia 82:546-556

Treuter D (2006) Significance of flavonoids in plant resistance: a review. Environ Chem Lett 4:147-157

Velioglu YS, Mazza G, Gao L, Oomah BD (1998) Antioxidant activity and total phenolics in selected fruits, vegetables, and grain products. Agric Food Chem 46:4113-4117

Verardo V, Arráez-Román D, Segura-Carretero A, Marconi E, FernándezGutiérrez A, Caboni MF (2010) Identification of buckwheat phenolic compounds by reverse phase high performance liquid chromatography electrospray ionization-time of flight-mass spectrometry (RP-HPLC-ESI-TOF-MS). J Cereal Sci 52:170-176

Wang YC, Yang YS (2007) Simultaneous quantification of flavonoids and triterpenoids in licorice using HPLC. J Chromatogr B 850: 392-339 